\title{
Strategic Transfer Pricing, Absorption Costing and Vertical Integration
}

\author{
Robert F. Göx* \\ University of Magdeburg
}

May 28, 1998

\begin{abstract}
This paper analyzes the use of transfer pricing as a strategic device in divisionalized firms facing duopolistic price competition. When transfer prices are observable, both firms' headquarters will exclude their marketing division from the external input market and charge a transfer price above the market price of the intermediate product to induce their marketing managers to behave as softer competitors on the final product market. When transfer prices are not observable, strategic transfer pricing is not an equilibrium and the optimal transfer price equals the market price of the intermediate product. As an alternative, the firms can signal their competitor a transfer price above the market price of the intermediate input through a proper choice of their accounting system. The paper identifies conditions under which the choice of absorption costing is a dominant strategy for both firms. Moreover, when the firms' products are close substitutes, the strategic benefits of full cost based transfer pricing can provide incentives to maintain a production department that would not be able to survive as a separate firm in the long run.
\end{abstract}

Key Words: Transfer Pricing, Absorption Costing, Vertical Integration.

JEL: D43, L13, L22, M40.

*Dipl.-Kfm. Robert F. Göx, Otto-von-Guericke-University of Magdeburg, Faculty of Economics and Management, PF 4120, 39016 Magdeburg. Tel.: +49/391/6718729, Fax: + 49/391/6711136, Email: goex@ww.uni-magdeburg.de 


\section{Introduction}

A common problem for vertically integrated firms is the coordination of activities among divisions in order to achieve an efficient allocation of resources within the organization. This task typically involves the determination of transfer prices for those goods and services that are exchanged on the divisional level. According to Hirshleifer (1956) the transfer pricing problem is easily solved in presence of a perfectly competitive intermediate good market by setting the transfer price equal to the market price of the intermediate product. However, under these circumstances a firm's headquarters may allow their managers to negotiate the terms of internal trade or perform all transactions on the external market. Since internal and external trade are perfect substitutes, all these alternatives yield the same performance, provided the divisional managers are free to perform unlimited (and costless) transactions on the external market. Furthermore, under these conditions there is actually neither a need for transfer pricing nor for vertical integration because each division could also act as a separate firm and attain the same profit level.

In contrast, this paper demonstrates that market-based transfer pricing may not be optimal when the final product market is imperfectly competitive. In a modified HIRSHLEIFER setting with two identical firms facing price competition on the final product market, both firms earn strictly higher profits when they charge transfer prices above the market price of the intermediate product. The intuition behind strategic transfer pricing is easily explained. Consider the Nash equilibrium in a price setting duopoly market. Both competitors would prefer to charge higher prices because any collusive strategy resulting in prices between the noncooperative equilibrium and the cartel solution increases both firms' profits. The problem is that cooperative agreements require either an enforceable contract or credible precommitments to be feasible. Since cartel contracts are illegal and tacit collusion usually provides incentives to cheat, owner-managed firms are in general confined to the noncooperative equilibrium ${ }^{1}$.

This reasoning also holds for vertically integrated firms in the case of centralized decision making. Consider the regular case of a divisionalized firm where the firm's headquarters delegates the pricing decision to a division manager and evaluates the agent's performance by his divisional profit. Since the transfer price is an exogenous parameter to the agent's profit maximization problem, headquarters can commit him to the desired high-price strategy by rising the transfer price above the market price of the intermediate good. Conversely, a centralized firm could not credibly commit itself to the agents' strategy because the market price of the intermediate good is exogenous to its decision problem and hence, choosing the manager's equilibrium strategy would not be a profit maximizing

\footnotetext{
${ }^{1}$ See JAQUEMin AND Slade (1988), p. 417. In a multiperiod setting, firms may carry out irreversible investments to create credible precommittments see e.g. BRANDER AND SPENCER (1983). But these may be to costly to carry out and hence incredible see TIROLE (1988), chapter 8 , for a review of related models.
} 
strategy for the centralized firm. Thus, the strategic benefits of delegation imply a strict preference for decentralization over centralization.

The idea behind strategic transfer pricing is closely related to a branch of the industrial organizations literature pursued by Vickers (1985), FERSHTMAN AND JudD (1987) and SKLIVAS (1987). Based on the pioneering work of SCHELLING (1960), these authors demonstrate the strategic benefits of incentive contracts as credible precommitments vis-a-vis a competitor when managers are allowed to play the market game on behalf of the owners ${ }^{2}$. The notion that accounting data may serve similar purposes has largely been overlooked in the management accounting literature, except recent studies provided by GAL-OR (1993) and Hughes AND KaO (1998). Both papers consider the impact of common service cost allocations on the optimal production policies of two multiple product firms facing both duopolistic quantity competition on the final product market and production externalities within the firm ${ }^{3}$. Although the specific shape of the "congestion" cost function assumed in these models prevents the derivation of general results, it becomes evident from numerical computations performed by HugHES AND KAO (1998) that decentralized firms are usually forcing their managers to behave as more aggressive competitors than centralized firms by employing a tidy cost allocation rule. The reason is that the tidyness requirement leads to an implicit subsidization of the firms' products as compared to the relevant costs under centralized decision making. As a result, both firms are earning strictly lower profits under decentralization except for some corner solutions where the whole congestion costs are allocated to one of the firms' profit centers ${ }^{4}$.

Strategic transfer pricing has only recently been explored by AlLES AND DaTAR (1998) and Göx (1998). Both authors analyze the case of cost based transfer pricing in absence of a market substitute for the intermediate product. While AlLEs AND Datar (1998) are focussing on price competition for the case of linear demands, the model of Göx (1998) also provides results for the case of quantity competition under more general demand conditions $^{5}$. Both authors find that the optimal transfer price under price competition contains a markup over marginal cost leading both firms' managers to raise their prices on

\footnotetext{
${ }^{2}$ The typical equilibrium contract that is offered to the firms' managers in theses models is a linear combination of profit and sales, see e.g. FERSHTMAN AND JUDD (1987).

${ }^{3}$ The major difference between both models is that the second division in GAL-OR (1993) operates on a perfectly competitive market while HUGHES AND KAO (1998) consider two duopolistic divisions acting on separate markets.

${ }^{4}$ Despite its inefficiency decentralization is still a dominant strategy equilibrium in many cases because a centralized firm would be worse off when it would have to compete against a decentralized competitor. Hence, the firms are usually facing a prisoner's dilemma, see HugHES AND KAO (1998), p. 277.

${ }^{5}$ The results of GÖX (1998) for the case of quantity competition are similar those of HUGHES AND KAO (1998). He demonstrates that both firms are charging transfer prices below the marginal cost of production to force their managers to more agressive behavior. Unlike the cost allocation case, the corresponding decentralization game is always a prisoners dilemma for the duopolists.
} 
the final product market to the mutual benefit of both firms. These findings are similar to the results of the basic model presented in the third section of this paper. However, given the existence of a perfectly competitive intermediate product market there is no leeway for the firms' headquarters to provide the desired managerial incentives by deviating from the market price without imposing restrictions on external trade.

A fundamental objection against the whole class of strategic delegation models refers to the observability of the competitor's incentive structure. As pointed out by KATZ (1991) and BAGWELL (1995), unobservable contracts cannot serve as credible precommitments unless they are employed for other than strategic reasons ${ }^{6}$. This observation limits the direct applicability of transfer pricing as a strategic device to the case of observable transfer prices. Although it may be a reasonable assumption that the firms in a small industry do know their competitor's transfer prices, it seems promising to identify strategic alternatives when the transfer prices are not common knowledge because establishing transfer prices above the market price of the intermediate product would be beneficial for both firms. In the last part of this paper it is demonstrated that a publicly observable commitment to an absorption costing system may create the desired managerial incentives because it allows the firms to signal their competitor a deviation from market based transfer pricing. However, since a full cost based transfer price can only exceed the market price of the intermediate product when the production department is not able to recover its full costs, absorption costing can only provide strategic benefits when the production department would not be able to survive as a separate firm in the long run. Thus, the strategic advantage of full cost based transfer pricing must be balanced against the possible cost savings from a production shutdown. This paper identifies conditions under which both absorption costing and integrating the unprofitable production department is a dominant strategy equilibrium.

Although the analysis assumes symmetric information within the organizations, the results draw a parallel to recent findings from the principal-agent literature ${ }^{7}$. Following Amershi And Cheng (1988) and VAYsman (1996), the optimal transfer pricing mechanism under asymmetric information is a "cost plus" type price schedule, consisting of a standard cost refund and a markup covering a profit share, an information premium and a compensation for the agent's effort. From the strategic point of view, these contracts are

\footnotetext{
${ }^{6}$ This does not rule out the possibility of killing two birds with one stone. A contract designed to enhance efficient risk sharing in an agency setting may as well create managerial incentives that are complementary with the strategic target of a firm, see HUGHES AND KAO (1997) for an example on forward contracting. A similar reasoning allows unobservable tidy cost allocation to provide strategic incentives in HUGHES AND KAO (1998).

${ }^{7}$ A substantial amount of the recent transfer pricing literature has dealt with various aspects asymmetric information including Ronen and Balachandran (1988), Christensen and Demski (1990), BankeR and Datar (1992), Wagenhofer (1994) or Edlin and Reichelstein (1995).
} 
not only complementary to the markup-rule in the case of duopolistic price competition, but also allow firms to signal a deviation from the intermediate product's market price for other than strategic reasons. Although a comprehensive analysis of these issues seems promising, it is beyond the scope of this study.

This rest of this paper is organized as follows. Section two outlines the model assumptions and analyzes the price strategies of two centralized firms. Section three provides the solution to the administered strategic transfer pricing policy assuming that transfer prices can be observed before agents make their pricing decisions. Section four enlarges the theme by considering the case of unobservable transfer prices and the impact of cost system choice on the firms' strategies. Section five provides an example based on a linear demand system and section six concludes the paper with a summary of results.

\section{Model assumptions and benchmark case}

\subsection{Market and cost structure}

Consider two vertically integrated firms $(i=1,2)$, each of them consisting of headquarters (HQ) and two divisions: the manufacturing division $A_{i}$ and the marketing division $B_{i}$. Each division is organized as a profit center and controlled by a manager, who is free in the operating decisions concerning his department and responsible for divisional performance. The production manager of firm $i$ will also be referred to as agent $A_{i}$ and the marketing manager as agent $B_{i}$. Division $A_{i}$ produces an intermediate product that serves as an input for division $B_{i}$ and can be traded in unlimited quantities in a perfectly competitive external market at a given market price $m$. The marketing division further processes the intermediate good and sells it in the final product market. In contrast to conventional transfer pricing models the market for the finished product is assumed to be imperfectly competitive. The market is exclusively served by the marketing divisions $B_{1}$ and $B_{2}$, each of them offering a different brand within a larger product class. Assuming price competition between the marketing divisions the market demand for the final product of department $B_{i}$, is a function of its own price $p_{i}$ and the competitor's price $p_{j}$. The demand function $q_{i}\left(p_{i}, p_{j}\right)$ is assumed to satisfy the usual properties in partial equilibrium analysis:

$$
\frac{\partial q_{i}}{\partial p_{i}}<0, \frac{\partial q_{i}}{\partial p_{j}}>0
$$

Since products are (weak) substitutes, demand for the final product of division $B_{i}$ falls with its own price $p_{i}$ and rises with the competitors' price $p_{j}$. Suppose also that the following conditions hold

$$
\frac{\partial q_{i}}{\partial p_{j}}=\frac{\partial q_{j}}{\partial p_{i}} \quad \text { and } \quad \frac{\partial q_{j}}{\partial p_{i}}<\left|\frac{\partial q_{i}}{\partial p_{i}}\right| .
$$


While the first condition in (2) exhibits the symmetry of cross effects on demand, the second states that both firms' products are not perfectly substitutable assuring that none of the firms can capture the entire market by marginally undercutting its rivals price ${ }^{8}$.

Suppose that both firms set a constant transfer prices per unit of the intermediate good, denoted by $t_{i}$. Since a deviation from the market price $m$ would lead one of the firms' agents to refuse internal trade, the possible gains from an administered transfer pricing policy cannot be achieved without restrictions on external trade. Thus, HQ is assumed to mandate internal trade in the following way: Agent $B_{i}$ is restricted to internal purchases, while Agent $A_{i}$ has free access to the external market. When the production quantity of the intermediate product, denoted by $x_{i}$, exceeds the marketing department's demand $q_{i}\left(p_{i}, p_{j}\right)$, agent $A_{i}$ is free to sell his excess production $y_{i}=x_{i}-q_{i}\left(p_{i}, p_{j}\right)$ to the external market. When $y_{i}<0$ instead, the production manager is allowed to fill up the gap between internal demand and his production from the external market. To simplify the analysis, let each final product unit require one unit of the intermediate good to be finished at a constant further processing cost of $c_{i}$ per unit. Under these conditions, agent $B_{i}$ faces the following profit maximization problem:

$$
\max _{p_{i}} \Pi_{i}^{B}=\left(p_{i}-c_{i}-t_{i}\right) q_{i}\left(p_{i}, p_{j}\right)
$$

To ensure the existence of a Nash equilibrium $p=\left(p_{i}^{*}, p_{j}^{*}\right)$ in the agents market game, the profit functions $\Pi_{i}^{B}$ are assumed to be strictly concave in each agents own price $p_{i}$. The equilibrium will be unique, when the following condition holds ${ }^{9}$ :

$$
\frac{\partial^{2} \Pi_{i}^{B}}{\partial p_{i}^{2}} \frac{\partial^{2} \Pi_{j}^{B}}{\partial p_{j}^{2}}-\frac{\partial^{2} \Pi_{i}^{B}}{\partial p_{i} \partial p_{j}} \frac{\partial^{2} \Pi_{j}^{B}}{\partial p_{j} \partial p_{i}}>0 .
$$

Given the preceding assumptions about internal trade it remains to specify the cost functions of the manufacturing divisions, which are given by $C_{i}\left(x_{i}\right)$ and assumed to be twice differentiable and strictly convex. Consistent with standard economic theory, the presence of diseconomies of scale provides an explanation for the prevailing market structure for the intermediate good. Accordingly, the profit function of division $A_{i}$ is given by

$$
\Pi_{i}^{A}=m x_{i}+\left(t_{i}-m\right) q_{i}\left(p_{i}, p_{j}\right)-C_{i}\left(x_{i}\right),
$$

where the first term in (5) denotes the revenue of division $A_{i}$ when it would sell its entire production to the external market and the second term designates the additional profit contribution from internal sales. Note, that nothing would be gained by introducing the

\footnotetext{
${ }^{8}$ This problem is also known as the Bertrand paradox and occurs in the case of identical products, see e.g. Tirole (1988).

${ }^{9}$ Although the Nash equilibrium is a static concept, the inequality (4) is also referred to as the condition for reaction function stabilty, because it ensures that any arbitrary price strategy $p=\left(p_{i}, p_{j}\right)$ converges against the Nash equilibrium in a myopic adjustment process, see e.g. DIXIT (1986), p.109.
} 
quantity of external trade as a decision variable in (5). Since the terms of internal trade are fixed for agent $A_{i}$, the optimal amount of external sales is automatically determined, when agent $A_{i}$ maximizes his divisional profit with respect to $x_{i}$. To provide a benchmark solution to the firm's allocation problem, consider first the case of centralized decision making.

\subsection{Centralized decision-making}

In the centralized setting $\mathrm{HQ}$ of firm $i$ chooses the quantity of the intermediate product and the pricing strategy on the final product market to maximize total profit

$$
\max _{p_{i}, x_{i}} \Pi_{i}=\Pi_{i}^{A}+\Pi_{i}^{B},
$$

where

$$
\Pi_{i}=\left(p_{i}-c_{i}-m\right) q_{i}\left(p_{i}, p_{j}\right)+m x_{i}-C_{i}\left(x_{i}\right)
$$

is easily obtained as the sum of (5) and (3). Maximizing (6) with respect to $p_{i}$ and $x_{i}$ yields the following first order conditions:

$$
\begin{aligned}
& \frac{\partial \Pi_{i}}{\partial p_{i}}=q_{i}\left(p_{i}, p_{j}\right)+\left(p_{i}-c_{i}-m\right) \frac{\partial q_{i}}{\partial p_{i}}=0 \quad i, j \in\{1,2\}, i \neq j, \\
& \frac{\partial \Pi_{i}}{\partial x_{i}}=m-\frac{\partial C_{i}}{\partial x_{i}}=0 \quad, i=1,2
\end{aligned}
$$

According to (8) the optimal production quantity $x_{i}^{*}$ is determined by equalizing the market price with the intermediate product's marginal cost. Moreover, the optimal production policy is obviously independent of the pricing decision due to the existence of a perfect market substitute for the intermediate product. The Nash equilibrium between both firms' HQ on the final product market is defined by the system of implicit reaction functions given by ( 7$)$. The vector of equilibrium prices, $p=\left(p_{i}^{*}, p_{j}^{*}\right)$, can be obtained as the solution of the system, provided a closed form solution does exist. The equilibrium condition can be rewritten as

$$
p_{i}^{*}=\frac{\left|\varepsilon_{i}\right|}{\left|\varepsilon_{i}\right|-1}\left(c_{i}+m\right) \quad \text { where } \quad \varepsilon_{i}=\frac{\partial q_{i}}{\partial p_{i}} \frac{p_{i}}{q_{i}},
$$

indicating that both firms mark up their marginal cost, $c_{i}+m$, by a constant factor that is determined solely by their own price elasticity of demand, designated by $\varepsilon_{i}$. Denote the equilibrium demands as $q_{i}^{*}=q_{i}\left(p_{i}^{*}, p_{j}^{*}\right)$, then the benchmark profit of firm $i$ under centralized decision-making can be expressed as

$$
\Pi_{i}^{*}=\left(p_{i}^{*}-c_{i}-m\right) q_{i}^{*}+m x_{i}^{*}-C_{i}\left(x_{i}^{*}\right)
$$

The resulting divisional profits could also be achieved by allowing both departments to act as two separate firms. Hence, the centralized setting is equivalent to a decentralized setting with free market access for both departments. However, given the existence of a 
competitor in the final product market the firms can improve their overall profitability by delegating the decision over the final product price to the marketing manager. The reason for this claim will become evident in the next section.

\section{$3 \quad$ Strategic transfer pricing}

\subsection{Game structure}

In this section the strategic transfer pricing game between both firms' headquarters is analyzed under the assumption that either manager can perfectly observe its competitor's transfer price before selecting his pricing strategy for the final product. The consequences of unobservable transfer prices will be discussed in section four. Given the observability assumption, the firm's maximization problem becomes a two stage game with perfect information. The game tree is depicted in figure 1.

Figure 1: Strategic transfer pricing game

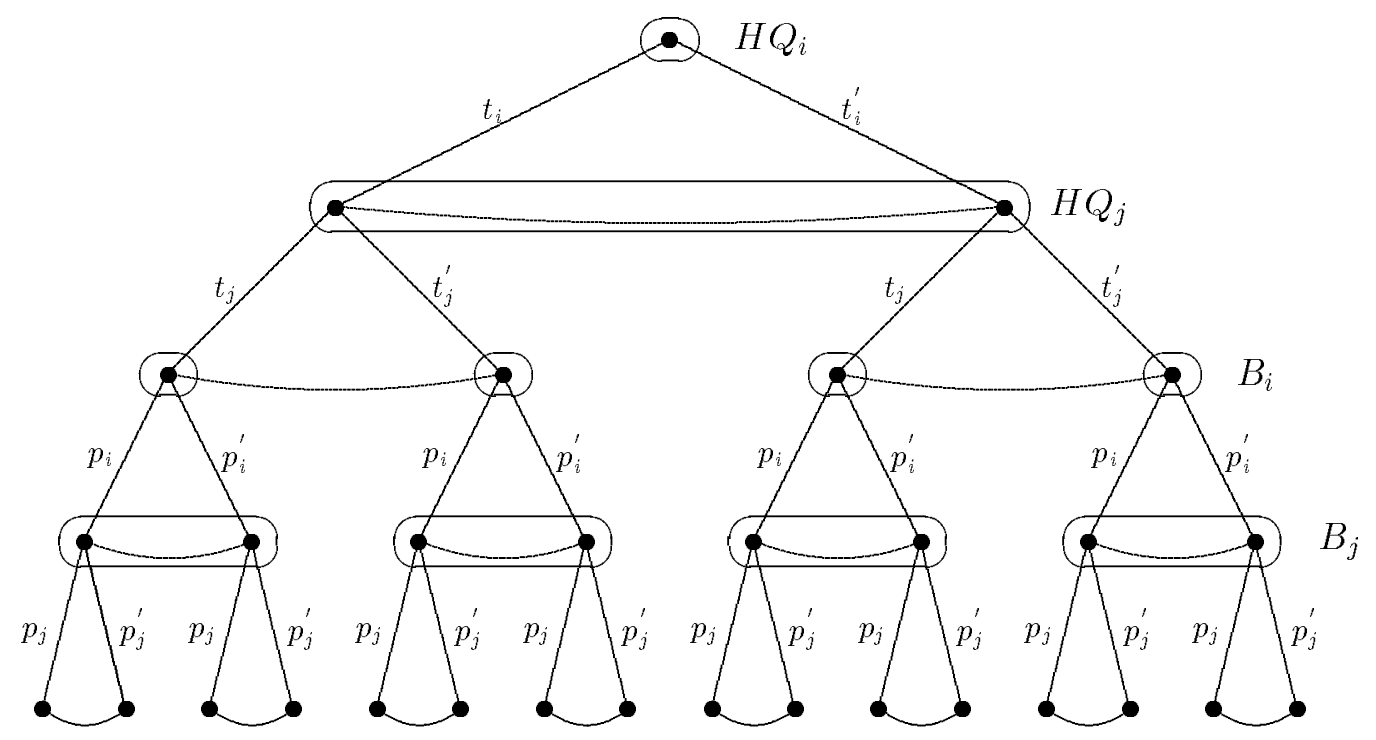

On the first stage of the game both firms' headquarters simultaneously choose their transfer prices $t_{i}$ and $t_{j}$. In figure 1 this fact is depicted by the oval containing the two nodes that follow the arbitrary transfer prices $t_{i}$ and $t_{i}^{\prime}$. In game theoretic terms both nodes belong to the same information set, indicating that player $H Q_{j}$ cannot distinguish between different moves of $H Q_{i}$. After the transfer prices have been chosen by headquarters both managers observe the outcome of the first stage before they simultaneously determine their pricing strategies on the second stage of the game. Although their role 
need not be considered explicitly for the solution of the transfer pricing game, it should be noted that the manufacturing departments are finally supposed to choose their optimal production quantities and to balance the difference between internal demand and their optimal production quantity by transactions on the intermediate product market.

\subsection{Equilibrium solution}

The solution of the two stage game is obtained by backward induction starting with the agents' production and pricing decisions on stage two. Consider first the production decision of Agent $A_{i}$. Since the production manager has free access to the intermediate good market, his optimal production decision is independent of the marketing department's demand. Hence, the optimal quantity of the intermediate good must equal the optimal quantity in the centralized setting ${ }^{10}$. The interesting part in the decentralized setting is the subgame between both firms' marketing departments. In this game agent $B_{i}$ first maximizes his divisional profit function (3) with respect to his own price $p_{i}$ for a given pricing choice $p_{j}$ of agent $B_{j}$. The resulting pair of first order conditions

$$
\frac{\partial \prod_{i}^{B}}{\partial p_{i}}=q_{i}\left(p_{i}, p_{j}\right)+\left(p_{i}-c_{i}-t_{i}\right) \frac{\partial q_{i}}{\partial p_{i}}=0, \quad i, j \in\{1,2\}, i \neq j
$$

implicitly defines the Nash equilibrium of the second stage market game between the marketing managers. For a given demand system the equilibrium solution $p^{*}=\left(p_{i}^{*}, p_{j}^{*}\right)$ is uniquely determined by both firms' transfer prices. Accordingly the equilibrium strategies can be written as

$$
p_{i}^{*}\left(t_{i}, t_{j}\right)=\underset{p_{i}}{\arg \max } \Pi_{i}^{B}\left(p_{i}, p_{j}^{*}, t_{i}\right) .
$$

The expression in (12) exhibits that the agents' equilibrium strategies are functions of both firms' transfer prices from the perspective of their headquarters. Hence, the distinguishing feature of transfer pricing vis-a-vis a competitor is the fact that the transfer price of firm $i$ does not only affect the pricing decision of agent $B_{i}$ but also the pricing strategy of agent $B_{j}$. In other words, the transfer price has a strategic effect. This effect is, however, an indirect one. To see this consider a small change of $t_{i}$. In the first place the change of the transfer price will affect the profitability of the marketing department $B_{i}$ and cause the manager to change his price $p_{i}$. Although the profit of the competitor's marketing department $B_{j}$ does not directly depend on $t_{i}$ the manager of department $B_{j}$ will react to his competitor's transfer pricing policy because the shift in the other agents' pricing strategy induced by the new transfer price $t_{i}$ has a direct impact on his profit. The directions of both the direct and the indirect effect of a change in one of the firms' transfer prices are stated in Lemma 1.

\footnotetext{
${ }^{10} \mathrm{It}$ is easy to see that the first order condition for the centralized setting in (8) also must hold for the maximization problem of division $A_{i}$ in (5).
} 
Lemma 1 The equilibrium prices chosen by the agents in the market game are strictly increasing in both firms' transfer prices

$$
\frac{\partial p_{i}}{\partial t_{i}}>0, \frac{\partial p_{j}}{\partial t_{i}}>0
$$

Proof See appendix.

Consider first the sign of the direct effect in Lemma 1. From the agent's first order condition (11) it is easy to check that an increase of $t_{i}$ is equivalent to an upward shift of the marketing department's marginal cost curve. Since the marginal revenue schedule remains unchanged, agent $B_{i}$ must increase his price $p_{i}$ to equate both curves at a lower output quantity for a given price of his competitor. The best response of Agent $B_{j}$ to this change in his competitor's price is to raise his own price $p_{j}$ as well. This is due to the fact that prices are strategic complements while quantities are strategic substitutes as observed by Bulow, Geanakoplos and Klemperer (1985). A more formal statement of this observation is the following condition

$$
\frac{\partial^{2} G_{i}}{\partial p_{i} \partial p_{j}}>0
$$

indicating that the marginal profit of firm $i$ increases when firm $j$ raises its price. As a consequence the intensity of competition is reduced and the market outcome moves closer to the cartel solution. Moreover, since condition (13) holds for either firm, the strategic effects will reinforce each other to the mutual benefit of both competitors when both firms increase their transfer prices.

From the preceding analysis we are now prepared to derive the first stage transfer pricing equilibrium between both firms' headquarters. Given the optimal pricing and production choices of the divisional managers both headquarters will maximize the sum of divisional profits

$$
\Pi_{i}^{*}=\Pi_{i}^{B *}+\Pi_{i}^{A *}
$$

with respect to their transfer prices, where $\Pi_{i}^{B *}$ and $\Pi_{i}^{A *}$ are given by

$$
\begin{aligned}
& \Pi_{i}^{A *}=m x_{i}^{*}+\left(t_{i}-m\right) q_{i}\left(p_{i}^{*}\left(t_{i}, t_{j}\right), p_{j}^{*}\left(t_{i}, t_{j}\right)\right)-C_{i}\left(x_{i}^{*}\right) \\
& \Pi_{i}^{B *}=\left(p_{i}^{*}\left(t_{i}, t_{j}\right)-c_{i}-t_{i}\right) q_{i}\left(p_{i}^{*}\left(t_{i}, t_{j}\right), p_{j}^{*}\left(t_{i}, t_{j}\right)\right):=V\left(t_{i}, t_{j}\right) .
\end{aligned}
$$

The notation $V\left(t_{i}, t_{j}\right)$ for the equilibrium profit of division $B_{i}$ in (16) is introduced to simplify the remaining steps of the analysis and to emphasize that not only equilibrium prices but also profits are functions of the transfer prices from the perspective of HQ. Expression (15) makes clear that the transfer pricing game is independent of the optimal production quantity $x_{i}^{*}$. The only term in the profit function of division $A_{i}$ relevant for this stage of the game is the surplus (loss) from internal transactions when the transfer price exceeds 
(falls below) the market price of the intermediate product. The necessary conditions for a Nash equilibrium between both firms' headquarters are obtained by differentiating total profit $\Pi_{i}^{*}$ with respect to the transfer price $t_{i}$

$$
\frac{\partial \Pi_{i}^{*}}{\partial t_{i}}=\frac{\partial V}{\partial t_{i}}+q_{i}^{*}+\left(t_{i}-m\right)\left(\frac{\partial q_{i}}{\partial p_{i}} \frac{\partial p_{i}^{*}}{\partial t_{i}}+\frac{\partial q_{i}}{\partial p_{j}} \frac{\partial p_{j}^{*}}{\partial t_{i}}\right)=0 \quad i, j \in\{1,2\}, i \neq j
$$

The partial derivative of the marketing departments profit with respect to the transfer price is given by

$$
\begin{aligned}
\frac{\partial V_{i}}{\partial t_{i}} & =\frac{\partial \Pi_{i}^{B}}{\partial p_{i}} \frac{\partial p_{i}}{\partial t_{i}}+\frac{\partial \Pi^{B}}{\partial p_{j}} \frac{\partial p_{j}}{\partial t_{i}}+\frac{\partial \Pi_{i}^{B}}{\partial t_{i}} \\
& =0+\left(p_{i}^{*}-c_{i}-t_{i}\right) \frac{\partial q_{i}}{\partial p_{j}} \frac{\partial p_{j}^{*}}{\partial t_{i}}-q_{i}^{*}
\end{aligned}
$$

where the first term must be zero from (11) because we are looking for the impact of transfer pricing on the agents' equilibrium strategies. The remaining two terms correspond to the indirect and direct effects of transfer pricing that have already been explained above. The last term $\partial \Pi_{i}^{B} / \partial t_{i}$ captures the direct reduction of divisional profit by an increase of marginal costs which is simply $-q_{i}^{*}$ according to Hotelling's Lemma. This effect would, however, also occur in a non-oligopolistic environment. The characteristic term for strategic transfer pricing is the second expression in (18). The term is strictly positive from Lemma 1 and the assumptions about the demand system in (1) and captures the profit impact of the competitors reaction to a change in division $B_{i}$ 's cost situation. Substituting (18) into (17) and solving for $t_{i}$ yields the following equilibrium solution of the transfer pricing game:

$$
t_{i}^{*}=m-\frac{\left(p_{i}^{*}-c_{i}-m\right) a}{b} \quad, a=\frac{\partial q_{i}}{\partial p_{j}} \frac{\partial p_{j}^{*}}{\partial t_{i}}>0 \quad, b=\frac{\partial q_{i}}{\partial p_{i}} \frac{\partial p_{i}^{*}}{\partial t_{i}}<0
$$

Proposition 1 The optimal transfer price exceeds the market price of the intermediate product by a strategic markup.

Proof: From Lemma 1 and (1) $a>0$ and $b<0$. Hence, the second term in (19) is negative

Substituting the optimal transfer price into the managers first order condition (11) and solving for $p_{i}$ yields the new equilibrium prices in the decentralized setting

$$
p_{i}^{*}=\frac{\left|\varepsilon_{i}\right|}{\left|\varepsilon_{i}\right|-1}\left(c_{i}+t_{i}^{*}\right)
$$

Since $t_{i}^{*}>m$ these are obviously higher than those in the centralized game given by equation (9). Moreover, from (13) and the symmetry assumption, both firms must also earn strictly higher profits than in the centralized setting. Thus, strategic transfer pricing 
can be regarded as an implicit form of tacit coordination because the overall intensity of competition on the final product market is lower than in the benchmark case of centralized firms. However, the new equilibrium can only be achieved in the decentralized setting. While both firms' headquarters can commit their marketing managers to act as "softer" competitors on the product market by charging a transfer price above the market price of the intermediate product, headquarters could not credibly commit themselves to the same strategy because the market price is an exogenous parameter of the firms profit function. Hence, any deviation from the Nash strategy in the centralized setting would be incredible because it would not be profit maximizing. A graphical analysis of the strategic transfer pricing equilibrium for the case of a linear demand system is depicted in figure 1 :

Figure 2: Strategic transfer pricing equilibrium

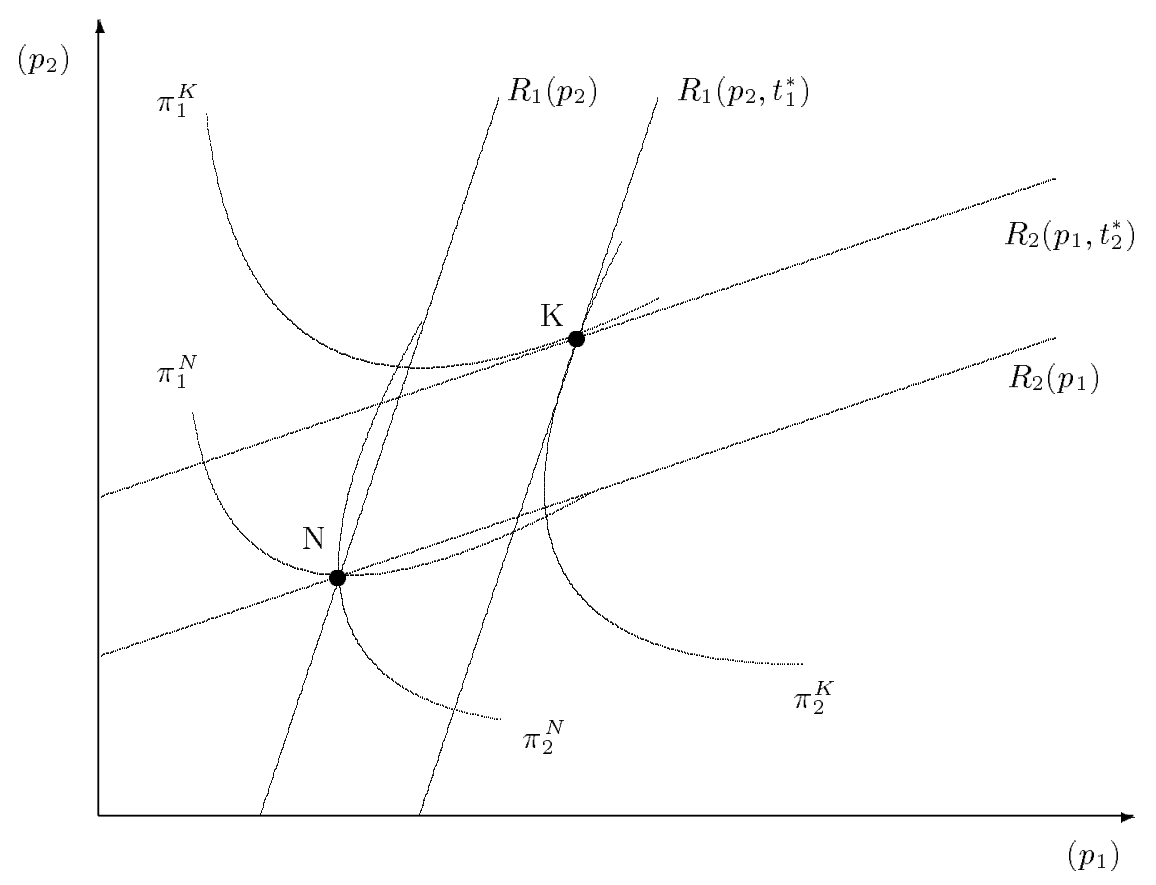

The analysis starts at point $N$, the Nash equilibrium under centralized decision making which is determined by the intersection of the reaction functions $R_{1}\left(p_{2}\right)$ and $R_{2}\left(p_{1}\right)$. Note that these reaction functions would coincide with those of the managers when the intermediate product would be transferred at its market price. The corresponding equilibrium profits are given by the isoprofit curves $\pi_{1}^{N}$ and $\pi_{2}^{N}$ respectively. When both headquarters adopt strategic transfer pricing policies the managers' reaction functions are shifted away from the origin arriving at the new equilibrium point $K$ where either firm's isoprofit curve has a tangency point with its competitor's reaction function. The new equilibrium is determined by the intersection of the reaction functions $R_{1}\left(p_{2}, t_{1}^{*}\right)$ and $R_{2}\left(p_{1}, t_{2}^{*}\right)$ with 
both firms charging higher prices and attaining higher profit levels than in the original equilibrium, which are given by the isoprofit curves $\pi_{1}^{K}$ and $\pi_{2}^{K}$.

\section{Unobservable transfer prices}

So far it has been assumed that managers perfectly observe their competitor's transfer price before their decisions about the pricing strategies for the final product. This may be a reasonable assumption for a small industry with similar products and relatively stable production and demand conditions where transfer prices are only subject to change within longer periods ${ }^{11}$. Since strategic transfer pricing is beneficial to both firms it may also be reasonable to suppose that the duopolists will disclose their transfer pricing practices voluntarily. This does not necessarily require that transfer pricing methods have to be reported in financial statements which would barely be consistent with common company practice. As will be shown in the last part of this section a proper choice of the accounting system which is very likely to be observed by competitors can serve similar purposes. However, in order to underscore the importance of information about the transfer pricing practice of the competitor we will first consider the extreme case of unobservable transfer prices.

\subsection{Game structure}

The extensive form of the strategic transfer pricing game with unobservable transfer prices is given in figure 3. Like the game with observable actions the game has two stages. The first stage consists of the two headquarters simultaneously choosing their transfer prices $t_{i}$ and $t_{j}$. In contrast two the original game in figure 1 the agents are asymmetrically informed about the outcome of the first stage. Each agent can only observe the transfer price of his own firm but not the transfer price of the competitor when he decides about his pricing strategy.. This fact is identifiable by the reduced number of information sets for both agents in figure 3. Agent $B_{i}$ for example, can only distinguish between the two arbitrary transfer prices $t_{i}$ and $t_{i}^{\prime}$ but not between the subsequent moves of $H Q_{j}$. Both nodes following the transfer prices $t_{j}$ and $t_{j}^{\prime}$ belong to the same information set. Hence, neither firm's headquarters can expect the other firm's manager to react directly to its transfer price since he cannot observe its predecessor's move. Nevertheless, each firm can still take influence on the pricing strategy of its own manager by deviating from the intermediate product's market price. Such manipulations must, however, be an equilibrium strategy for the firm's headquarters because otherwise a deviation from the

\footnotetext{
${ }^{11}$ Empirical evidence on transfer pricing practices of german firms indicate that a substantial amount of firms are revising their transfer prices on an annual basis only, see COENENBERG (1992), p. 471.
} 
Figure 3: Game tree for unobservable transfer prices

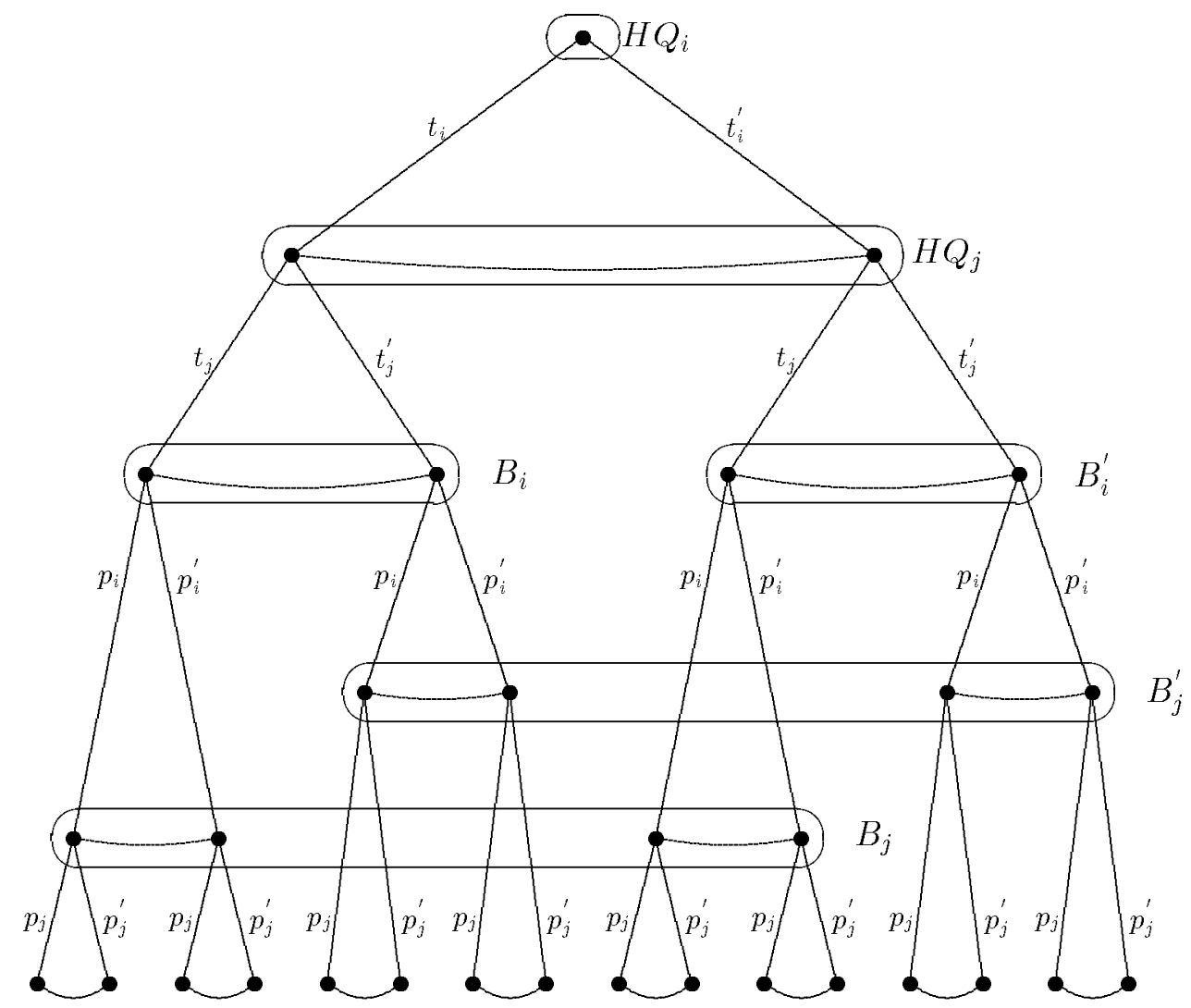

market price of the intermediate product would lead the marketing manager to suboptimal pricing decisions and thereby to a reduction of the firm's profit.

\subsection{Equilibrium strategies}

Since the only proper subgame of the game in figure 3 is the entire game, backward induction cannot be applied to solve for the equilibrium ${ }^{12}$. Rather, the equilibrium strategies of the four players must be based on rational conjectures about the other players' strategies like in a simultaneous game. Let us first consider the market game between both managers. Like in the observable transfer price game both agents first maximize divisional profits with respect to prices. Since divisional profits are not functions of the competitor's transfer price, there is no difference between the first order conditions of the managers' maximization problems between the case of observable and unobservable transfer prices. However, the reaction functions given by (11) are no longer sufficient to compute the equi-

\footnotetext{
${ }^{12}$ A proper subgame $S$ of an extensive-form game $E$ ist defined as a game that starts with a single node and contains all its successors in E, see FUd ENBERG and Tirole (1991), p. 94.
} 
librium strategies because neither manager knows the other firm's transfer price. While agent $B_{i}$ can derive his own reaction function $p_{i}^{*}\left(p_{j}, t_{i}\right)$ from (11) as a function of the other agent's price $p_{j}$ and his own transfer price $t_{i}$, he can only predict the other agent's profit maximizing price strategy by forming a rational conjecture $\hat{t}_{j}$ about the transfer price of his competitor. Given the presumed transfer price, manager $B_{i}$ can compute his optimal pricing strategy by substituting the conjectured reaction function $p_{j}^{*}\left(p_{i}, \hat{t}_{j}\right)$ into his own reaction function and solving for $p_{i}$. An equilibrium in the managers' market game is then given by the following pair of prices:

$$
p_{i}^{*}\left(p_{j}^{*}\left(p_{i}^{*}, \hat{t}_{j}\right), t_{i}\right) \quad \text { for } \quad i, j \in\{1,2\}, i \neq j .
$$

It should be immediate from (20) that the equilibrium price of manager $B_{i}$ is no longer a function of his competitor's transfer price $t_{j}$ like in the original game with observable transfer prices. Moreover, for an equilibrium of the whole game the managers' conjectures must be consistent with the profit maximizing transfer prices. These are obtained as the solution of the following problem faced by both firms' headquarters

$$
\max _{t_{i}} \Pi_{i}=\Pi_{i}^{B}\left(p_{i}^{*}\left(p_{j}, t_{i}\right), p_{j}, t_{i}\right)+m x_{i}^{*}+\left(t_{i}-m\right) q_{i}\left(p_{i}^{*}\left(p_{j}, t_{i}\right), p_{j}\right)-C_{i}\left(x_{i}^{*}\right) .
$$

In contrast to the observable transfer pricing game of the last section, the profit expression in (21) is a function of agent $B_{i}$ 's reaction function $p_{i}^{*}\left(p_{j}, t_{i}\right)$ and the competitor's price $p_{j}$ because $H Q_{i}$ can still manipulate the pricing strategy of agent $B_{i}$ but not the pricing strategy of agent $B_{j}$ by the choice of its transfer price. Since agent $B_{j}$ cannot observe $t_{i}$, the game between $H Q_{i}$ and $B_{j}$ is equivalent to a simultaneous move game, although the transfer price is actually set in advance ${ }^{13}$. Hence, the first order condition for the firm's optimization problem is given by:

$$
\frac{\partial \Pi_{i}}{\partial q_{i}}=\frac{\partial \Pi_{i}^{B}}{\partial p_{i}} \frac{\partial p_{i}}{\partial t_{i}}+\frac{\partial \Pi_{i}^{B}}{\partial t_{i}}+q_{i}^{*}+\left(t_{i}-m\right) \frac{\partial q_{i}}{\partial p_{i}} \frac{\partial p_{i}^{*}}{\partial t_{i}}=0
$$

Since the strategic effect of the original game in (18) vanishes, the first term must be zero from the agent's first order condition and $\partial \Pi_{i}^{B} / \partial t_{i}=-q_{i}^{*}$, the optimality condition (22) simplifies to

$$
t_{i}^{*}=m
$$

Like in the traditional HiRshLEIfER model the optimal transfer price equals the market price of the intermediate product. A deviation from this policy would only result in a suboptimal pricing strategy of Manager $B_{i}$ without offering any strategic benefits. Moreover, the only conjectures consistent with this result are

$$
\widehat{t}_{i}=t_{i}^{*}
$$

\footnotetext{
${ }^{13}$ Indeed the fact that a subsequent player cannot observe his predecessor's action in a sequental game is equivalent to playing simultaneously, see FUdENBERG and TiRole (1991), pp. 70.
} 
Together the conditions (20), (23) and (24) define the unique Nash equilibrium of the whole game. Hence, given the information structure of the game it can neither be optimal for one of the firms to use a strategic transfer price nor can it be rational for one of the agents to conjecture a strategic deviation from the intermediate product's market price.

\subsection{Full cost based transfer pricing as a strategic device}

The introduction of a new accounting system usually requires substantial investments for software, employee training or consulting services. Accordingly the choice of an accounting system possesses the character of a long term commitment and is very likely to be observed by the competitors in a small market. Moreover, empirical studies indicate that a remarkable number of firms are using full cost systems for various purposes like product costing, performance evaluation and also for transfer pricing ${ }^{14}$. Thus, it seems reasonable to assume that the cost system choice also determines the nature of transfer prices utilized by a firm.

Although conventional wisdom suggests that the use of full cost based transfer prices is not optimal for divisionalized firms, their use can be rational for firms facing duopolistic price competition when the transfer price exceeds the market price. Otherwise there will be no strategic advantage because any transfer price below the market price of the intermediate product will force the marketing managers to behave more aggressively in the market game by lowering their prices. As a consequence the resulting firm profits would fall below the benchmark profit under centralized decision making. On the other hand, the requirement that the production department's full unit costs must exceed the market price of the intermediate product implies that the production department would not be able to survive as a separate firm in the long run. This raises the question if the firm would not be better off when it would forgo the possible strategic advantages and shut down the production department instead, provided that resigning from production is possible in the short run. For now it will, however, be assumed that both firms will continue to produce the intermediate product although its production is not profitable per se.

Suppose that both competitors must choose an accounting system before determining their transfer prices. The alternatives under consideration are absorption costing and variable costing. Without loss of generality it will be assumed that a firm which employs a marginal cost system will set the transfer price equal to the opportunity costs of the intermediate product ${ }^{15}$ which are given by the external market price $m$. When firm $i$

\footnotetext{
${ }^{14}$ According to Horngren/Foster/Datar (1994), p. 872, between 37 and 41 percent of U.S. firms are using transfer prices based on full costs for their internal transactions.

${ }^{15}$ Given the assumed strong convexity of the cost function the market price must also equal the marginal cost of production evaluated at the optimal quantity $x_{i}^{*}$.
} 
employs absorption costing instead, the transfer price will be set equal to the intermediate product's total manufacturing costs evaluated at the budgeted volume $\bar{x}_{i}$ per budgeted product unit. The transfer price under absorption costing will then be given by

$$
\bar{t}_{i}=C_{i}\left(\bar{x}_{i}\right) / \bar{x}_{i}>m
$$

and must exceed the market price $m$ by assumption. Suppose that the cost system choice becomes common knowledge before the market stage of the game. Then, the managers can conclude the corresponding transfer price from their knowledge about the competitor's accounting system. This does not necessarily imply that the transfer price under absorption costing given by (25) must be perfectly observable. Rather, it is sufficient when manager $B_{j}$ knows that $\bar{t}_{i}$ will exceed the market price of the intermediate product. Consider for example the case where agent $B_{j}$ is not informed about the exact value of the budgeted volume $\bar{x}_{i}$ but knows the cost function $C_{i}(\cdot)$ with certainty. To compute the Bayesian Nash equilibrium of the game, both managers must form subjective probability distributions over the possible values of the budgeted production volumes of their competitors and then replace $\bar{x}_{i}$ in (25) by its expectation $\hat{x}_{i}$. Based on his expectations about budgeted volume agent $B_{j}$ can determine the expected transfer price $\hat{t}_{i}$ of his competitor and the optimal pricing strategy of manager $B_{i}$ given the expected transfer price $\hat{t}_{i}$.

There are two questions remaining. The first one is under what conditions one of the firms will prefer absorption costing over variable costing. Hence, we are looking for a dominant strategy equilibrium for the first stage of the modified game. Obviously, absorption costing is the dominant system choice when firm $i$ 's expected profit from using full cost based transfer pricing exceeds expected profit from market based transfer pricing regardless of its competitors accounting system. Hence, the following condition must be satisfied:

$$
\hat{\Pi}_{i}^{*}\left(\bar{t}_{i}, t_{j}\right) \geq \hat{\Pi}_{i}^{*}\left(m, t_{j}\right) \quad \text { for } \quad t_{j} \in\left\{m, \hat{t}_{j}\right\}
$$

where $\hat{\Pi}_{i}^{*}$ is the expectation of (14), $\bar{t}_{i}$ is the transfer price of firm $i$ under absorption costing given by (25) and $\hat{t}_{j}$ is the expected full cost based transfer price of the competitor. Since the firms' profit functions are concave in their own transfer prices, condition (26) must hold for all transfer prices between the market price and the strategic transfer price $t_{i}^{*}$ given by (19). Moreover, due to the concavity of the profit function, condition (26) will also hold for some transfer prices $\bar{t}_{i}$ beyond $t_{i}^{*}$ because the profit attainable by market based transfer pricing will still be exceeded. The second question refers to the trade-off between the strategic benefits from full costing and the possible gains from a production shutdown. Since the profit of a firm not engaged in the production of the intermediate product simply equals the profit of division $B_{i}$ under market based transfer pricing, the following condition must be met to favor the strategic benefits from integrating the unprofitable division over the cost savings from non-integration

$$
\hat{\Pi}_{i}^{*}\left(\bar{t}_{i}, t_{j}\right) \geq \hat{\Pi}_{i}^{B *}\left(m, t_{j}\right) \quad \text { für } \quad t_{j} \in\left\{m, \hat{t}_{j}\right\} .
$$


Condition (27) is obviously stronger than (26) because

$$
\hat{\Pi}_{i}^{*}\left(m, t_{j}\right)-\hat{\Pi}_{i}^{B *}\left(m, t_{j}\right)=\hat{\Pi}_{i}^{A *}\left(m, t_{j}\right)<0
$$

from (25). Thus, when integration is optimal for firm $i$ the choice of a full cost system must also be a dominant strategy on the first stage of the game. However, a general assessment of the conditions under which a firm would prefer integration is impossible without further assumptions about the cost and demand structure. The next section provides an example with linear demands that allows to identify the optimal policies for both firms.

\section{$5 \quad$ Example}

\subsection{Assumptions and benchmark case}

Consider a duopoly with the following linear demand system

$$
q_{i}=\gamma-p_{i}+\beta p_{j} \quad i, j \in\{1,2\}, i \neq j,
$$

where $\beta \in(0,1)$ must hold to satisfy assumption (2) and $\gamma>m(1-\beta)$ is assumed to ensure the existence of an interior Nash equilibrium under centralized decision making. To simplify the analysis the further processing costs of the marketing departments are normalized to zero while the production costs of the intermediate product are represented by the following quadratic cost function

$$
C_{i}\left(x_{i}\right)=x_{i}^{2}+F \text {. }
$$

Under these assumptions the profit functions of the divisions in firm $i$ are given by

$$
\begin{aligned}
\Pi_{i}^{A} & =m x_{i}+\left(t_{i}-m\right)\left(\gamma-p_{i}+\beta p_{j}\right)-x_{i}^{2}-F \\
\Pi_{i}^{B} & =\left(p_{i}-t_{i}\right)\left(\gamma-p_{i}+\beta p_{j}\right) .
\end{aligned}
$$

Consider first the Nash equilibrium in the centralized setting. Maximizing the sum of divisional profits with respect to $p_{i}$ and $x_{i}$ yields the following solutions for the equilibrium prices and optimal production quantities of the intermediate products

$$
\begin{aligned}
x_{i} & =\frac{m}{2}, \quad p_{i}=m+\frac{\delta}{2-\beta} \\
\text { where } \delta & =\gamma-m(1-\beta)>0 .
\end{aligned}
$$

Substituting these solutions into the profit function yields the benchmark profit of the centralized firm

$$
\Pi_{i}^{*}(m, m)=\left(\frac{\delta}{2-\beta}\right)^{2}+\frac{m^{2}}{4}-F,
$$


where the first term in (33) is the profit contribution of the marketing Division $B_{i}$ and the last two terms represent the profit of the production division $A_{i}$. Throughout the analysis it will be supposed that the following conditions hold

$$
\Pi_{i}^{*}(m, m)>0 \quad \text { and } \quad \Pi_{i}^{A *}(m, m)=\frac{m^{2}}{4}-F<0 .
$$

The first assumption is simply a participation constraint for the centralized firm. The second condition will be required to satisfy condition (25) in case of a full cost system and states that the production department would be unprofitable as a separate firm.

\subsection{Strategic transfer pricing equilibrium}

When both firms delegate the pricing decision to division managers and transfer prices are observable, the tow step optimization procedure described in section 3 applies. First, both marketing managers maximize their divisional profits given by (30) with respect to their own prices and solve for $p_{i}$ to obtain their reaction functions

$$
p_{i}\left(p_{j}\right)=\frac{\gamma+t_{i}+\beta p_{j}}{2} .
$$

These functions are obviously increasing in both their own transfer price $t_{i}$ and the competitors' price $p_{j}$. Solving the system of reaction functions for $p_{1}$ and $p_{2}$ yields the following equilibrium strategies

$$
p_{i}^{*}\left(t_{i}, t_{j}\right)=\frac{\gamma}{2-\beta}+\frac{2 t_{i}+\beta t_{j}}{4-\beta^{2}}, \quad i, j \in\{1,2\}, i \neq j .
$$

Observe, that the managers' equilibrium prices are increasing functions of the transfer prices from the perspective of both firms' $\mathrm{HQ}$ as indicated in (12). Note also that the direct effect of $t_{i}$ on the equilibrium price $p_{i}$ exceeds the indirect effect of $t_{j}$ which in turn increases with $\beta$, the parameter measuring the degree of product substitutability. It is easily checked that the managers' equilibrium prices would only coincide with the price equilibrium of the two centralized firms given by (32) if both HQ would set their transfer prices equal to the market price of the intermediate product. Substituting the equilibrium strategies of the second stage game into the profit function yields the first stage profit function of firm $i$ :

$$
\begin{aligned}
\Pi_{i}^{*}\left(t_{i}, t_{j}\right) & =q_{i}^{*}\left(t_{i}, t_{j}\right)^{2}+\left(t_{i}-m\right) q_{i}^{*}\left(t_{i}, t_{j}\right)+\Pi_{i}^{A *}(m, m) \\
\text { where } \quad q_{i}^{*}\left(t_{i}, t_{j}\right) & =\frac{\gamma}{2-\beta}-\frac{\left(2-\beta^{2}\right) t_{i}-\beta t_{j}}{4-\beta^{2}} .
\end{aligned}
$$

The first term in (37) is the book profit of division $B_{i}$ while the sum of the last two terms represent the accounting profit of division $A_{i}$. Since $q_{i}^{*}\left(t_{i}, t_{j}\right)$ is decreasing in both firms' transfer prices, the profit of the marketing division will be lower under strategic 
transfer pricing than under market based transfer pricing. Moreover, because the net effect of strategic transfer pricing on firm profits is positive and $\Pi_{i}^{*}(m, m)>0$, the production divisions' loss under market-based transfer pricing must be more than compensated. Thus, the accounting income of division $A_{i}$ will be positive under strategic transfer pricing. To compute the transfer pricing equilibrium of the first stage game both firms HQ maximize their profit functions given by (37) with respect to their transfer price. The symmetric Nash equilibrium is obtained by solving the resulting pair of first order conditions for $t_{1}$ and $t_{2}$ :

$$
t_{i}^{*}=m+\frac{\delta \beta^{2}}{4-2 \beta-\beta^{2}} \quad i \in\{1,2\} .
$$

Since $\delta>0$ and $\beta \in(0,1)$ the optimal transfer prices given by (38) are obviously larger than the market price of the intermediate product and strictly increasing with the similarity of final products, measured by $\beta$. Substituting the optimal transfer prices of both competitors into (37) and rearranging terms yields the equilibrium profit of firm $i$ :

$$
\Pi_{i}^{*}\left(t_{i}^{*}, t_{j}^{*}\right)=\left(1+\frac{(4-3 \beta) \beta^{3}}{\left(4-2 \beta-\beta^{2}\right)^{2}}\right) \Pi_{i}^{B *}(m, m)+\Pi_{i}^{A *}(m, m) .
$$

It should be obvious from (39) that $\Pi_{i}^{*}\left(t_{i}^{*}, t_{j}^{*}\right)$ strictly exceeds $\Pi_{i}^{*}(m, m)$ for values of $\beta>0$ and assumes its maximum when $\beta$ approaches the value of one ${ }^{16}$. Thus, the strategic benefits of transfer pricing are the largest for both competitors when their products are close substitutes.

\subsection{Full cost pricing}

Assume for simplicity that the budgeted volumes of both firms are equal to the optimal production quantities of the intermediate product given by (32) and that there is no uncertainty between firms. Hence, we have $\bar{x}_{i}=x_{i}^{*}$ and the full cost based transfer price will be given by

$$
\bar{t}_{i}=m+v \quad \text { where } \quad v=\frac{4 F-m^{2}}{2 m},
$$

where the full cost markup, denoted by $v$, must be positive from the second assumption in (34). Let us first evaluate the optimal cost system choice of the integrated firm. Thus, we will ignore for the moment the possibility of abandoning the unprofitable department and check if the profit of firm $i$ under full cost transfer pricing, given by

$$
\Pi_{i}^{*}\left(\bar{t}_{i}, t_{j}\right)=q_{i}^{*}\left(\bar{t}_{i}, t_{j}\right)^{2}+v q_{i}^{*}\left(\bar{t}_{i}, t_{j}\right)+\Pi_{i}^{A *}(m, m),
$$

exceeds the profit of firm $i$ under marginal costing,

$$
\Pi_{i}^{*}\left(m, t_{j}\right)=q_{i}^{*}\left(m, t_{j}\right)^{2}+\Pi_{i}^{A *}(m, m)
$$

\footnotetext{
${ }^{16}$ Note that $\lim _{\beta \rightarrow 1} \Pi_{i}^{*}\left(t_{i}^{*}, t_{j}^{*}\right)=2 \Pi_{i}^{B *}(m, m)+\Pi_{i}^{A *}(m, m)$.
} 
for a given transfer price $t_{j} \in\left\{m, \bar{t}_{j}\right\}$ of firm $j$. The equilibrium demands on the final product market for the four possible cases are easily obtained by substituting the transfer prices resulting from the two possible cost system choices of both firms into the general expression for the equilibrium quantities in (37). The results are exhibited in table $1:{ }^{17}$

Table 1: Equilibrium demands for given accounting systems

\begin{tabular}{|c|c|c|}
\hline & $t_{i}=m$ & $t_{i}=\bar{t}_{i}$ \\
\hline$t_{j}=m$ & $q_{i}^{*}(m, m)=\frac{\delta}{2-\beta}$ & $q_{i}^{*}\left(\bar{t}_{i}, m\right)=q_{i}^{*}(m, m)-\frac{v\left(2-\beta^{2}\right)}{4-\beta^{2}}$ \\
\hline$t_{j}=\bar{t}_{j}$ & $q_{i}^{*}\left(m, \bar{t}_{j}\right)=q_{i}^{*}(m, m)+\frac{v \beta}{4-\beta^{2}}$ & $q_{i}^{*}\left(\bar{t}_{i}, \bar{t}_{j}\right)=q_{i}^{*}(m, m)-\frac{v(1-\beta)}{2-\beta}$ \\
\hline
\end{tabular}

Consider first the case where the competitor relies on marginal costing and sets the transfer price $t_{j}=m$. The profit of firm $i$ under this condition is depicted by the curve $\Pi_{i}\left(m, t_{j}\right)$ in figure 4. Since the profit of firm $i$ is concave in its own transfer price and

Figure 4: Admissible full cost markups

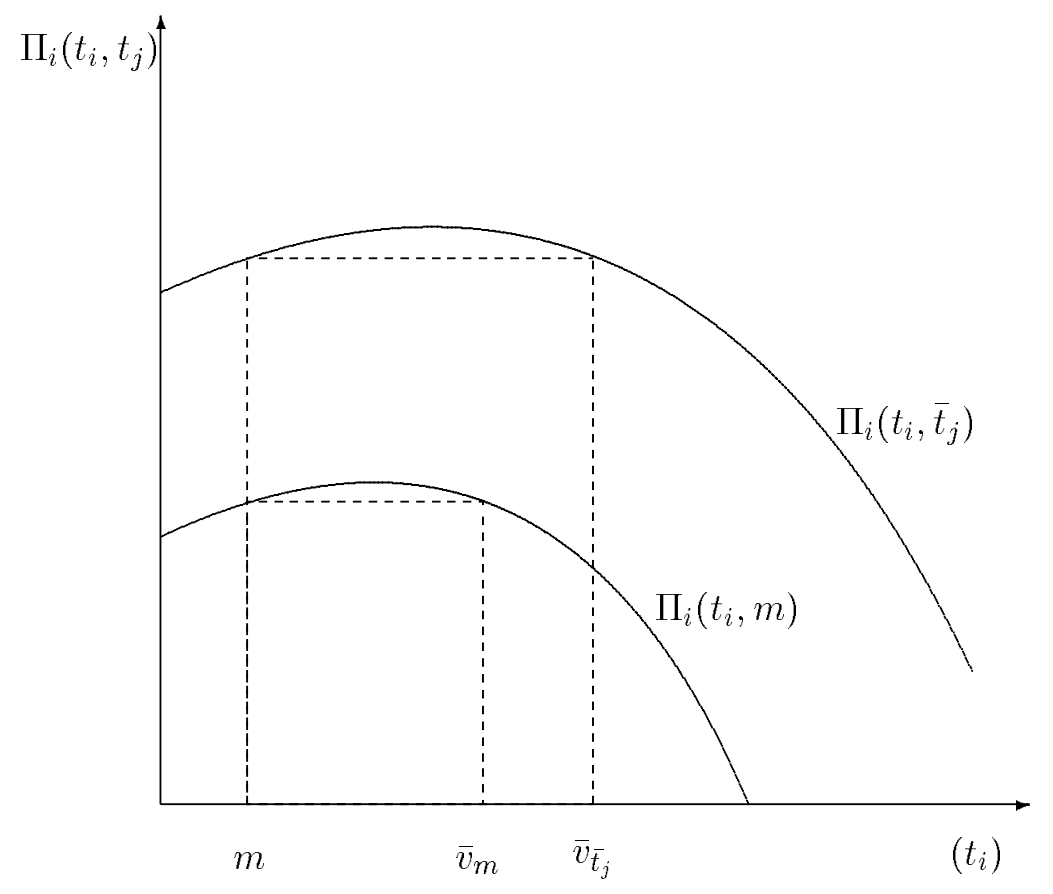

the market price $m$ is below the optimal transfer price at the peak of the curve, a shift towards the right will increase the firm's profit until the full cost markup reaches the

\footnotetext{
${ }^{17}$ Note that $q_{i}^{*}\left(m, \bar{t}_{j}\right)>q_{i}^{*}(m, m)$ although both competitors are charging higher prices when firm $j$ employs absorption costing. The reason is that, the positive effect of the increase in $p_{j}$ on $q_{i}$ outweighs the negative effect of the increase in $p_{i}$. Hence, $p_{i}^{*}\left(m, \bar{t}_{j}\right)-p_{i}^{*}(m, m)<\beta\left(p_{i}^{*}\left(m, \bar{t}_{j}\right)-p_{i}^{*}(m, m)\right)$.
} 
critical value $\bar{v}_{m}$. When firm $j$ employs a full cost system instead and charges a transfer price $t_{j}=\bar{t}_{j}$, the profit curve of firm $i$ will incur an upward shift because the profit of firm $i$ is strictly increasing in $t_{j}$. Hence, the allowable full cost markup moves to the right up to the point denoted by $\bar{v}_{\bar{t}_{j}}$. The intuition behind this effect is easily explained. Since prices are strategic substitutes and a higher transfer price of firm $j$ leads its manager to rise his price, the marginal revenue of firm $i$ will also increase and allow firm $i$ to induce a higher final product price by increasing the transfer price. The critical values for the admissable full cost markups under both scenarios are easily computed by solving the inequality $\Pi_{i}^{*}\left(\bar{t}_{i}, t_{j}\right)>\Pi_{i}^{*}\left(m, t_{j}\right)$ for a given transfer price of the competitor:

$$
\bar{v}_{m}=\frac{\delta(2+\beta) \beta^{2}}{4-2 \beta^{2}}<\frac{\delta(2+\beta) \beta^{2}}{4-2 \beta^{2}-\beta^{3}}=\bar{v}_{\bar{t}_{j}}
$$

The choice of a full cost system is, however, only a dominant strategy for firm $i$ when $v<\bar{v}_{m}$ although both competitors would attain higher profits by charging a full cost markup $v \in\left(\bar{v}_{m}, \bar{v}_{\bar{t}_{j}}\right)$. Unfortunately, the choice of accounting systems with markups between $\bar{v}_{m}$ and $\bar{v}_{\bar{t}_{j}}$ cannot be implemented in dominant strategies because the mutual best response to marginal costing is marginal costing by symmetry. Since this observation is also true for absorption costing, the accounting system choice game has two Nash equilibria, $\left(t_{1}^{*}=\bar{t}_{1}, t_{2}^{*}=\bar{t}_{2}\right)$ and $\left(t_{1}^{*}=t_{2}^{*}=m\right)$. One may, however, argue that the firms would play the pareto superior full cost equilibrium but in general it is not clear which equilibrium will be chosen.. Nevertheless, a dominant strategy equilibrium is more likely to exist, when the products are close substitutes because the admissible markup $\bar{v}_{m}$ is again increasing with the products' similarity and assumes its maximum as $\beta$ approaches one ${ }^{18}$.

So far we have not considered the possibility of a production shut down. However, when the performance of the production department cannot be improved in the long run and the firm can give up the production without incurring additional costs like compensations for the loss of offices, it may prefer to abandon the production department. On the other hand, the firm forgoes the opportunity to manipulate the pricing strategy of its marketing manager by charging a full cost based transfer price. Hence, the sourcing decision must consider the trade-off between the production department's loss and the forgone benefits of full cost transfer pricing. According to condition (27) the profit under full cost based transfer pricing must exceed the marketing department's profit under market based transfer pricing for a given accounting system choice of the competitor. Since we know from the preceding considerations that the profit of firm $i$ is strictly increasing in $t_{j}$, we can restrict our attention to the case of marginal costing by firm $j$. Hence, the relevant condition for firm $i$ to maintain production is

$$
q_{i}^{*}\left(\bar{t}_{i}, m\right)^{2}+v q_{i}^{*}\left(\bar{t}_{i}, m\right)+\Pi_{i}^{A *}(m, m) \geq q_{i}^{*}(m, m)^{2},
$$

${ }^{18}$ Substituting for $\delta$ yields the maximum admissible markup: $\lim _{\beta \rightarrow 1} v_{m}=\frac{3}{2} \gamma$. 
where the first two terms on the left hand side represent the net strategic benefit from full cost transfer pricing, the third term is the loss of division $A_{i}$ and the term on the right hand side would be the profit of the marketing division acting as a separate firm. Since the strategic benefits and the loss of the production division are both increasing with the fixed costs of Division $A_{i}$, it makes sense to ask for the largest admissible value of $F$ that leaves the firm indifferent between integration and outsourcing. Utilizing the definition of the full cost markup in (40) and the equilibrium demand given in table 1 we are ready to solve condition (42) for the critical value of $F$ :

$$
\frac{m^{2}}{4}+\frac{(2+\beta)\left[2 m \gamma \beta^{2}-m^{2}\left(8-4 \beta-\beta^{3}\right)\right]}{16-8 \beta^{2}}>F
$$

The first term on the left hand side of (43) is the profit from the market transactions of division $A_{i}$ and the second term represents the net surplus from full cost based transfer pricing over the non-integrated profit of division $B_{i}$. Since $F>m^{2} / 4$ must be satisfied to employ full cost based transfer pricing as a strategic device, only the second term is relevant. When it is positive, firm $i$ will prefer to integrate division $A_{i}$ despite its lacking profitability. Since the sign of the strategic term is determined be the expression in squared brackets, we can derive the following relation to find the firms' optimal sourcing decision:

$$
\frac{\gamma}{m}>\frac{\left(8-4 \beta-\beta^{3}\right)}{2 \beta^{2}}:=\Psi .
$$

Taking the relevant limits of $\Psi$ with respect to $\beta$ yields:

$$
\lim _{\beta \rightarrow 1} \Psi=\frac{3}{2} \quad \text { and } \quad \lim _{\beta \rightarrow 0} \Psi=\infty .
$$

Thus the ratio of the demand function parameter $\gamma$, which may be interpreted as the market size of the duopoly, and the market price of the intermediate product must be at least $3 / 2$ to favor integration when the products are close substitutes. On the other hand, the required ratio must approach infinity when the products become more differentiated. Since this notion seems unrealistic, there will exist a critical value of $\beta$ for a given demand situation on both markets below which a firm would prefer the production shutdown. Again product substitutability governs the relative merits of the strategic effect.

\subsection{Numerical results}

This subsection will provide some numerical results to illustrate the preceding considerations. Assume the parameter values $\gamma=800, m=200$ and $F=20,000$ yielding the following results for the full cost markup, the full cost based transfer price and the profit of the production division $A_{i}$ :

$$
v=200, \quad \bar{t}_{i}=400, \quad \Pi_{i}^{A *}=-10,000 .
$$


Since the products' substitutability has been identified as the critical factor in determining the optimal transfer pricing policy of the firms, table 2 exhibits the profits resulting from the alternative policies for different values of the parameter $\beta$ :

Table 2: Firm profits and product substitutability

\begin{tabular}{|l|c|c|c|}
\hline \multicolumn{1}{|c|}{$\beta$} & 0.3 & 0.6 & 0.9 \\
\hline$\Pi_{i}^{*}(m, m)$ & 140,727 & 254,490 & 492,810 \\
\hline$\Pi_{i}^{B *}(m, m)$ & 150,727 & 264,490 & 502,810 \\
\hline$\Pi_{i}^{*}\left(\bar{t}_{i}, m\right)$ & 132,519 & 254,760 & 519,465 \\
\hline$\Pi_{i}^{*}\left(m, \bar{t}_{j}\right)$ & 152,877 & 289,486 & 576,017 \\
\hline$\Pi_{i}^{*}\left(\bar{t}_{i}, \bar{t}_{j}\right)$ & 144,740 & 290,408 & 605,537 \\
\hline$\Pi_{i}^{*}\left(t_{i}^{*}, t_{j}^{*}\right)$ & 141,878 & 275,601 & 739,439 \\
\hline
\end{tabular}

The relevant expressions for the evaluation of the firms' dominant strategies are the profits in the first three rows. For relatively weak substitutes $(\beta=0.3)$ we observe the relation

$$
\Pi_{i}^{B *}(m, m)>\Pi_{i}^{*}(m, m)>\Pi_{i}^{*}\left(\bar{t}_{i}, m\right) .
$$

Since both the profit under non-integration and the integrated profit under market based transfer pricing are larger than the profit from unilateral absorption costing, marginal costing is the dominant strategy for the integrated firm and outsourcing dominates integration when it is feasible. While the last observation also holds for intermediate substitutes $(\beta=0.6)$, the integrated firm will prefer absorption costing over marginal costing because

$$
\Pi_{i}^{B *}(m, m)>\Pi_{i}^{*}\left(\bar{t}_{i}, m\right)>\Pi_{i}^{*}(m, m) .
$$

When products are close substitutes $(\beta=0.9)$ absorption costing still dominates marginal costing but non-integration is no longer optimal because the strategic benefits of full cost based transfer pricing exceed the loss of the production department. Thus, we have the relation

$$
\Pi_{i}^{*}\left(\bar{t}_{i}, m\right)>\Pi_{i}^{B *}(m, m)>\Pi_{i}^{*}(m, m)
$$

for similar products. Since the game is symmetric, both firms will choose absorption costing on the first stage of the game and the profit will be $\Pi_{i}^{*}\left(\bar{t}_{i}, \bar{t}_{j}\right)=605,537$ which is below the profit attainable in the case of observable transfer prices, given by $\Pi_{i}^{*}\left(t_{i}^{*}, t_{j}^{*}\right)=$ 739,439 . However, even if transfer prices were observable, absorption costing would be the best strategy for integrated firms for intermediate values of $\beta$. Figure 5 shows that the profit under symmetric absorption costing, given by the solid line, exceeds the profit under observable strategic transfer pricing, given by the dotted line, for values of $\beta \in$ $[0.245,0.732]$. Since $t_{i}^{*}<\bar{t}_{i}$ for $\beta<0.732$, full cost pricing leads to higher prices and profits because installing an absorption costing system works like a precommitment for 
Figure 5: Full cost versus strategic transfer pricing

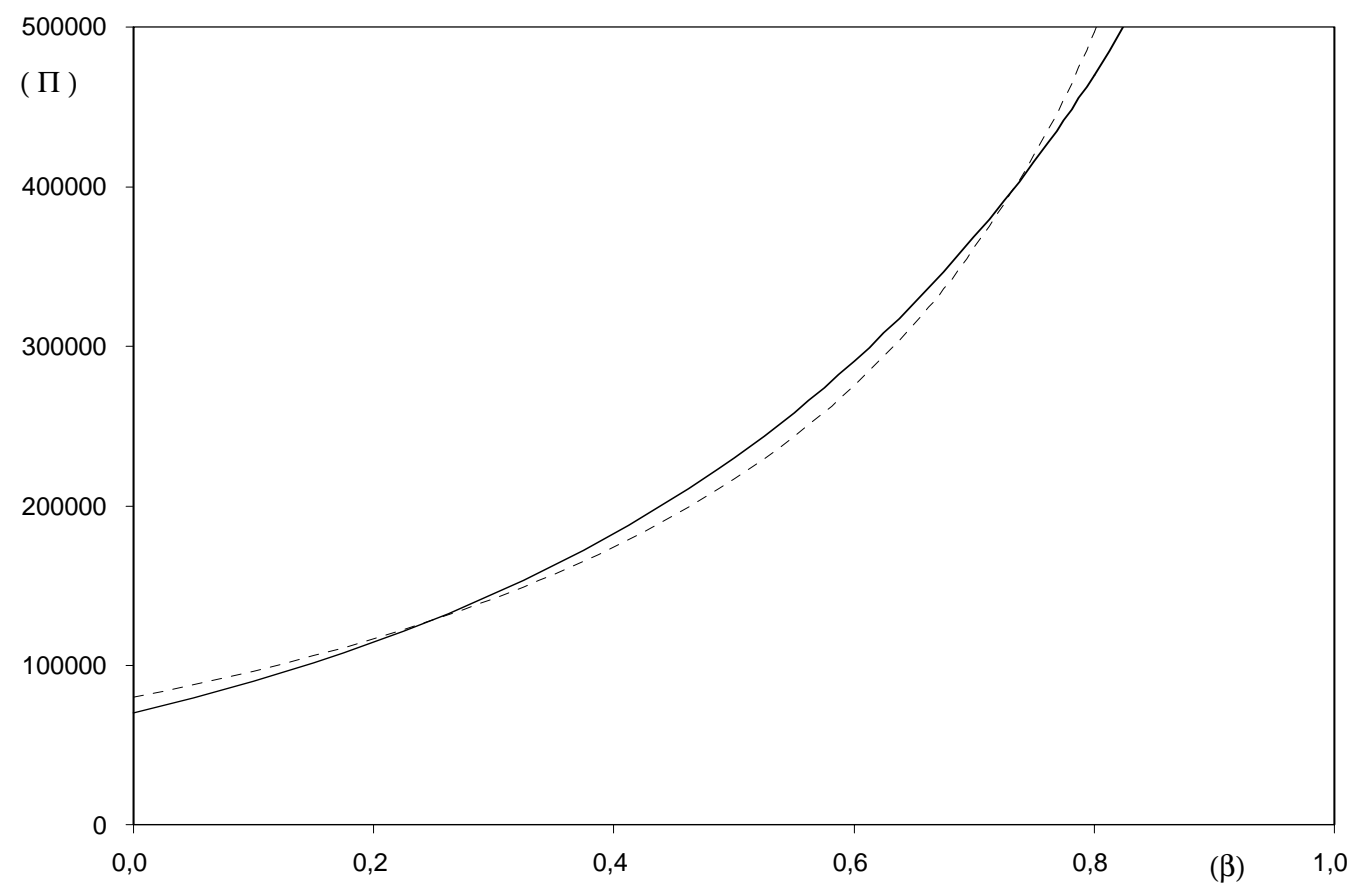

both firms' HQ to charge transfer prices above their equilibrium strategies in the noncooperative transfer pricing game under observable transfer prices.

\section{Summary}

This paper has analyzed the use of transfer pricing as a strategic device in divisionalized firms facing duopolistic price competition. When transfer prices are observable both firms' headquarters will charge a transfer price above the market price of the intermediate product to induce their marketing managers to behave as softer competitors on the final product market. In addition, the marketing departments must be excluded from the external input market because otherwise they would have no incentive to buy internally. Since the resulting equilibrium profits are strictly exceeding the profits attainable by two centralized firms the result provides an economic rationale for the use of transfer pricing that is not available in traditional transfer pricing models.

When transfer prices are not observable, strategic transfer pricing is not an equilibrium and the optimal transfer price equals the market price of the intermediate product like in the classical HiRshleifer model. The reason is that neither firm can take influence 
on the equilibrium strategy of the other firm's manager and thus a deviation from the market price of the intermediate product would only result in a suboptimal pricing decision of the own manager. Nevertheless, as a strategic alternative the firms can signal their competitor a transfer price above the market price of the intermediate input through a proper choice of its accounting system. This paper identifies conditions under which the choice of absorption costing is a dominant strategy equilibrium for the firms. Although the existence of the equilibrium depends on the degree of product substitutability, full cost based transfer pricing could be identified as the optimal policy under conditions where conventional wisdom would recommend market based transfer pricing.

Moreover, since the full cost based transfer price can only exceed the market price of the intermediate product when the production department is unprofitable per se, the firm faces a trade-off between realizing the strategic benefits from full cost based transfer pricing and the cost savings from outsourcing the unprofitable department. The paper demonstrates that vertical integration is a dominant strategy when the firms' products are close substitutes although the production department would not be able to survive as a separate firm in the long run. 


\section{References}

Alles, Michael/Datar, Srikant (1998): Strategic Transfer Pricing, forthcoming in Management Science, Vol. 44.

Amershi, Amin H./Cheng, Peter (1990): Intrafirm Resource Allocation: The Economics of Transfer Pricing and Cost Allocations in Accounting, Contemporary Accounting Research, Vol. 7, p. 61-99.

Bagwell, Kyle (1995): Commitment and Observability in Games, Games and Economic Behavior, Vol. 8, p. 271-280.

Banker, Rajiv D./Datar, SRikant M. (1992): Optimal Transfer Pricing under Postcontract Information, Contemporary Accounting Research, Vol. 8, No. 2, p. 329352.

Brander, J. A. And B. J. Spencer (1983). Strategic Commitment with R\&D: The Symmetric Case, Bell Journal of Economics, Vol. 14, p. 225-235.

Bulow, Jeremy I./Geanakoplos, John D./Klemperer, Paul D. (1985): Multimarket Oligopoly: Strategic Substitutes and Complements, Journal of Political Economy, Vol. 93, No. 3, p. 488-511.

Coenenberg, Adolf G. (1992): Kostenrechnung und Kostenanalyse, Landsberg am Lech.

Christensen, John,/Demski Joel F. (1989): Transfer Pricing in a limited communication setting, working paper, Odense and Yale University.

DiXit, Avinash (1986): Comparative Statics for Oligopoly, International Economic Review, Vol. 27, No. 1, p. 107-122.

Edlin, Aaron S./Reichelstein, Stefan (1995): Specific Investment under Negotiated Transfer Pricing: An Efficiency Result, Accounting Review, Vol. 70, No. 2, p. $275-291$.

Fershtman, Chaim/Judd, Kenneth L. (1987): Equilibrium Incentives in Oligopoly, The American Economic Review, Vol. 77, No. 5, p. 927-940.

Fudenberg, Drew/Tirole, Jean (1991): Game Theory, Cambridge/London.

Göx, Robert F. (1998a): Pretiale Lenkung als Instrument der Wettbewerbsstrategie, Zeitschrift für Betriebswirtschaftliche Forschung, Vol. 50, p. 260-288.

GaL-Or, Esther (1993): Strategic Cost Allocation, The Journal of Industrial Economics, Vol. 39, No. 4, p. 387-402. 
Hirshleifer, JaCK (1956): On the Economics of Transfer Pricing, Journal of Business, p. $172-184$.

Horngren, Charles T./Foster, George /Datar, Srikant M. (1994): Cost Accounting - A Managerial Emphasis, 8th editon, Englewood Cliffs NJ.

Hughes, John S./Kao, Jennifer L. (1997): Strategic forward contracting and observability, International Journal of Industrial Organization, Vol. 16, p. 121-133.

Hughes, John S./Kao, Jennifer L. (1998): Cross Subsidization, Cost Allocation, and Tacit Coordination, Review of Accounting Studies, Vol. 2, p. 265-293.

Jaqemin, Alexis/ Slade Margaret, E. (1989), Cartels, Collusion and Horizontal Merger, in: Schmalensee, Richard/Willig, Robert D. (EDs.), Handbook of Industrial Organization, Vol. I, p. 415-473.

Katz, Michael L. (1991): Game-playing Agents: Unobservable Contracts as Precommitments, Rand Journal of Economics, Vol. 22, No. 3, p. 201-228.

Ronen, Joshua/Balachandran, Kashi R. (1988): An Approach to Transfer Pricing Under Uncertainty, Journal of Accounting Research, Vol. 26, No. 2, p. 300-314.

Schelling, Thomas C. (1960): The Strategy of Conflict, Cambridge.

Sklivas, Steven D. (1987): The Strategic Choice of Managerial Incentives, Rand Journal of Economics, Vol. 18, No. 3, p. 452-458.

Tirole, JeAn (1988): The Theory of Industrial Organization, Cambridge/London.

Vaysman, Igor (1996): A Model of Cost-based Transfer Pricing, Review of Accounting Studies, Vol. 1, No. 1, p. 73-108.

Vickers, John (1985): Delegation and the Theory of the Firm, Economic Journal, Vol. 95, p. 138-147.

Wagenhofer, Alfred (1994): Transfer Pricing under Asymmetric Information - An Evaluation of Alternative Methods, European Accounting Review, Vol. 1, p. 71-104. 


\section{Appendix: Proof of Lemma 1}

Lemma 1: The equilibrium prices chosen by the agents in the market game are strictly increasing in both firms' transfer prices.

Proof: Totally differentiating the system of implicit reaction functions

$$
\frac{\partial \Pi_{i}^{B}\left(p_{i}, p_{j}, t_{i}\right)}{\partial p_{i}}=0, \quad i, j \in\{1,2\}, i \neq j
$$

defined in (11) yields

$$
\begin{aligned}
& \frac{\partial^{2} \Pi_{1}^{B}}{\partial p_{1}^{2}} d p_{1}+\frac{\partial^{2} \Pi_{1}^{B}}{\partial p_{1} \partial p_{2}} d p_{2}+\frac{\partial^{2} \Pi_{1}^{B}}{\partial p_{1} \partial t_{1}} d t_{1}=0 \\
& \frac{\partial^{2} \Pi_{2}^{B}}{\partial p_{2} \partial p_{1}} d p_{1}+\frac{\partial^{2} \Pi_{2}^{B}}{\partial p_{2}^{2}} d p_{2}+\frac{\partial^{2} \Pi_{2}^{B}}{\partial p_{2} \partial t_{2}} d t_{2}=0
\end{aligned}
$$

Applying Cramer's rule to the system of total differentials yields

$$
d p_{i}=\frac{1}{k}\left(\frac{\partial^{2} \Pi_{j}^{B}}{\partial p_{j} \partial p_{i}} \frac{\partial^{2} \Pi_{j}^{B}}{\partial p_{j} \partial t_{j}} d t_{j}-\frac{\partial^{2} \Pi_{i}^{B}}{\partial p_{i}^{2}} \frac{\partial^{2} \Pi_{i}^{B}}{\partial p_{i} \partial t_{i}} d t_{i}\right)
$$

where

$$
k=\frac{\partial^{2} \Pi_{1}^{B}}{\partial p_{1}^{2}} \frac{\partial^{2} \Pi_{2}^{B}}{\partial p_{2}^{2}}-\frac{\partial^{2} \Pi_{2}^{B}}{\partial p_{2} \partial p_{1}} \frac{\partial^{2} \Pi_{1}^{B}}{\partial p_{1} \partial p_{2}}>0
$$

from assumption (4). Since

$$
\frac{\partial^{2} \Pi_{j}^{B}}{\partial p_{j} \partial p_{i}}>0, \quad \frac{\partial^{2} \Pi_{i}^{B}}{\partial p_{i} \partial t_{i}}=-\frac{\partial q_{i}}{\partial p_{i}}>0 \quad \text { and } \quad \frac{\partial^{2} \Pi_{i}^{B}}{\partial p_{i}^{2}}<0
$$

from (13),(1) and the concavity of the profit function and

$$
d p_{i}=\frac{\partial p_{i}^{*}\left(t_{i}, t_{j}\right)}{\partial t_{i}} d t_{i}+\frac{\partial p_{i}^{*}\left(t_{i}, t_{j}\right)}{\partial t_{j}} d t_{j}
$$

we obtain the desired results for the signs of the strategic effects

$$
\begin{aligned}
& \frac{\partial p_{i}^{*}\left(t_{i}, t_{j}\right)}{\partial t_{i}}=\left.\frac{d p_{i}}{d t_{i}}\right|_{d t_{j}=0}=-\frac{1}{k} \frac{\partial^{2} \Pi_{i}^{B}}{\partial p_{i}^{2}} \frac{\partial^{2} \Pi_{i}^{B}}{\partial p_{i} \partial t_{i}}>0 \\
& \frac{\partial p_{i}^{*}\left(t_{i}, t_{j}\right)}{\partial t_{j}}=\left.\frac{d p_{i}}{d t_{j}}\right|_{d t_{i}=0}=\frac{1}{k} \frac{\partial^{2} \Pi_{j}^{B}}{\partial p_{j} \partial p_{i}} \frac{\partial^{2} \Pi_{j}^{B}}{\partial p_{j} \partial t_{j}}>0
\end{aligned}
$$

